\title{
Exclusiones del canon. Reflexiones sobre un caso argentino: el folletín de El Orden de Tucumán (1883-1900)*
}

\author{
Ana María Risco**
}

Recibido: 25 de enero de 2016

Evaluado: 1 de marzo de 2016

Aceptado: 1 de abril de 2016

\section{RESUMEN}

La producción literaria que circulaba en la prensa de las provincias de Argentina durante el siglo xIx y principios del xx ha sido poco estudiada en comparación con la rioplatense, considerada por sí misma representativa de la literatura argentina. Constatamos esta situación en el caso particular de la provincia de Tucumán, al noroeste del país. El escaso interés por el estudio del folletín como sección de la prensa escrita y como producto literario que fomenta la lectura ha llevado a la crítica a considerar esta sección como irrelevante. El presente trabajo parte de la identificación de la sección del folletín del periódico El Orden de Tucumán como espacio no solo de reproducción de literatura extranjera, sino también de producción local que dinamiza el ámbito cultural. Esta propuesta aborda las contradictorias posturas de exclusión-inclusión de la crítica literaria local desde mediados y fines del siglo xx y principios del xxI sobre la literatura publicada en diarios de provincias, centrado en el caso particular de Tucumán.

Desde los marcos teórico-conceptuales de la sociología de la cultura y la historia intelectual se emplea acá como metodología de estudio el análisis de los presupuestos de la crítica en las

Artículo de investigación. Cómo citar este artículo: Risco, A. M. (2016). Exclusiones del canon. Reflexiones sobre un caso argentino: el folletín de El Orden de Tucumán (1883-1900). Hallazgos, 13(26), 41-61 (doi: http://dx.doi.org/10.15332/s1794-3841.2016.0026.02).

** Doctora en Letras de la Universidad Nacional de Tucumán (Argentina). Investigadora en el Consejo Nacional de Investigaciones Científicas y Técnicas (ConICET) de Argentina. Correo electrónico: anamrisco@gmail.com Dirección postal: Casilla de Correo Argentino Nº64 -Casa Central- San Miguel de Tucumán, CP4000, Provincia de Tucumán, Argentina. El presente es un artículo de investigación derivado de un trabajo más amplio. 
valoraciones sobre la existencia de producción literaria en Tucumán del siglo xix. Entre las hipótesis planteadas, se arriesga la presencia de un centro metropolitano académico (Buenos Aires) que construye el canon literario argentino válido para investigar. Las posturas de los estudiosos locales varían en el transcurso de los años, desde una actitud tradicional hacia la resitencia.

Palabras clave: folletín, periodismo, estudios literarios, literatura argentina, Tucumán, canon literario. 


\section{Exclusions of the canon. Reflections about an Argentinian case: The feuilleton of El Orden from Tucumán (1883-1900)}

Received: January 25, 2016

Evaluated: March 1, 2016

Accepted: April 1, 2016

\section{Abstract}

The literary production that flow in the newspapers of the provinces from Argentina during the end of the $19^{\text {th }}$ Century and the beginning of $20^{\text {th }}$ Century has been poorly studied in comparison with the literature from Buenos Aires and its zone of influence that was considered as the representative literature of Argentina. We verify this situation in the particular case of province of Tucumán: the scarce interest in the study of the feuilleton of the press and in its consideration as a literary product has made invisible this section for the critics. The present paper analyzes the contradictions in the literary critic about the newspaper serial as a place of literary production and reproduction in Tucumán in this epoch.

In this paper we apply the theoretical and conceptual terms of the cultural sociology and intellectual history. The methodology of this study is to analyze the critical arguments about the existence of literary production in Tucumán in $19^{\text {th }}$ Century. Our hypothesis is that exist a metropolitan center (in Buenos Aires) that establishes a literary canon, and that determines its validity for research. The position of the local researchers varies in time from a traditional attitude to the resistance.

Keywords: Feuilleton, journalism, literary studies, literature of Argentina, Tucumán, literary canon. 


\section{Exclusões do cânone. Reflexões sobre um caso argentino: o folhetim de El Orden de Tucumán (1883-1900)}

\section{Resumo}

A produção literária que circulava na imprensa das províncias da Argentina durante o século XIX e começos do XX tem sido pouco estudada em comparação com a rio-platense, considerada por si mesma representativa da literatura argentina. Constatamos esta situação no caso particular da província de Tucumán, no nordeste do país. O escasso interesse pelo estudo do folhetim como seção da imprensa escrita e como produto literário que fomenta a leitura tem levado a crítica a considerar esta seção como irrelevante. O presente trabalho parte da identificação da seção do folhetim do jornal El Orden de Tucumán como espaço não só de reprodução de literatura estrangeira, senão também de produção local que dinamiza o âmbito cultural. Esta proposta aborda as contraditoras posturas de exclusão-inclusão da crítica literária local desde meados e finais do século XX e começos do XXI sobre a literatura publicada em jornais de províncias, focado no caso particular de Tucumán.

Desde os marcos teórico-conceptuais da sociologia da cultura e a história intelectual se utiliza aqui como metodologia de estudo a análise dos pressupostos da crítica nas valorações sobre a existência de produção literária em Tucumán do século XIX. Entre as hipóteses propostas, a presença de um centro metropolitano acadêmico (Buenos Aires) que constrói o cânone literário argentino valido para pesquisar. As posturas dos estudiosos locais variam no percurso dos anos, desde uma atitude tradicional até a resistência.

Palavras-chave: folhetim, jornalismo, estudos literários, literatura argentina, Tucumán, cânone literário.
Recebido: 25 de janeiro de 2016

Avaliado: 1 de março de 2016

Aceito: 1 de abril de 2016 
Pinta tu aldea y pintarás el mundo

L. Tolstoi

\section{INTRODUCCIÓN: PRESENTACIÓN DEL CASO, JUSTIFICACIÓN Y METODOLOGÍA}

En las dos últimas décadas de fines del siglo xIx el diario El Orden de Tucumán presenta una sección predominantemente literaria, "El Folletín de El Orden", cuya regularidad de publicación es variable. Este estudio integra tanto la reproducción como la producción de literatura local, nacional y extranjera que propone dicho periódico. Ambos procesos, el de la difusión de la producción y el de la reproducción de textos literarios de diversas épocas y lugares, se manifiestan como una modalidad de la recepción literaria resignificada por el medio periodístico como oferta de lectura y, por lo tanto, resultan pertinentes para el análisis de las relaciones entre periodismo y literatura. En este sentido, se sigue la premisa enunciada por Lisa Block de Behar (1984), quien sostiene que "la historia de la literatura constituye la obra de los lectores" y no solo "la de sus autores" (p. 50).

Siguiendo esta línea de investigación, se encontraron 66 textos literarios publicados en la sección "Folletín de El Orden" de Tucumán entre 1883 y 1900, algunos de ellos anónimos, la mayoría firmados. Un alto porcentaje de dichos textos son reproducciones de literatura extranjera (40 de un total de 66 obras literarias por entrega), una minoría (17) son de autores locales que gravitan en el espacio rioplatense, y sorpresivamente algunos de estos textos pertenecen a escritores que residen en la provincia de Tucumán y a jóvenes tucumanos que se atreven a enviar una contribución o alguna traducción de manera anónima.

De un total de 64 firmas, 17 corresponden a autores del ámbito francés de diversas épocas (entre los que figuran Jules Verne, Pontsevrez, Catulle Mendès, Louis Callet y Alfred Musset) y 17 gravitan en el terreno literario argentino (entre ellos, Pedro Goyena, Paul Groussac, Alberto García Hamilton, Rainerio J. Lugones y Olegario V. Andrade). Dichas cifras no contemplan el lugar de origen de los autores, sino fundamentalmente el circuito periodístico o literario de su trayectoria personal. Cada grupo representa aproximadamente el 26,5\% del total de las firmas. Por lo que puede observarse, los textos de autores que provienen de los terrenos literarios francés y argentino predominan en igual medida en el diario por encima del resto de las firmas provenientes de otros circuitos de producción y reproducción literarias, también de diversas épocas. Así, hay textos de circuitos literarios de países como España (Emilia Pardo Bazán y Ramón de Campoamor, entre otros), Estados Unidos de Norteamérica (entre quienes figuran Edgar Allan Poe y Wilkie Collins), Inglaterra (William Archer y Ellen Wood), Alemania (por ejemplo, Paul Brockmann), Italia (Eduardo Scarfoglio) y Rusia (Alexader S. Puschkin). De los países latinoamericanos, solo se encuentra representada Sudamérica a través de Uruguay y Brasil, países que se presentan integrados al ámbito literario rioplatense y argentino. Los circuitos literarios de los demás países latinoamericanos están ausentes en esta sección del diario tucumano durante el periodo señalado, aunque se encuentran firmas de autores de otras latitudes de América Latina dispersas 
en el cuerpo central del diario, como las de José Martí, Rubén Darío,Teodosio Estrada, Gimón Sterling y Soledad Acosta de Samper, entre otros.

Este reencuentro de textos que vieron la luz en la prensa tucumana de fines del siglo xIx lleva a la presente reflexión y la constatación de las primeras hipótesis de investigación sobre la existencia de un material olvidado y descuidado por los investigadores locales y nacionales, y la formulación de hipótesis explicativas sobre su exclusión de los estudios literarios. Este desinterés conduce a reflexionar sobre la validez de gravitar circularmente sobre lo ya establecido como canónico, sobre los mismos autores y temas, sin hacer ingresar el diálogo con lo relegado o postergado. Evidentemente, esta actitud excluyente y dominante implica una suspensión en el campo científico de las humanidades del avance de recuperaciones y redescubrimientos que aporten nuevos códigos de lectura y nuevas claves de interpretación, tanto del pasado como del presente y del futuro.

La intención de este trabajo no es realizar un análisis exhaustivo de los textos literarios publicados en la sección del folletín de El Orden de Tucumán, sino presentar un panorama crítico, una reflexión y la formulación de hipótesis explicativas acerca del escaso tratamiento académico de los folletines, como una sección de la prensa y como género literario, a partir de los siguientes interrogantes: ¿cuál es el modo de abordaje apropiado para textos publicados en la sección del folletín de El Orden que no son elaborados en su totalidad por escritores locales, ni tratan exclusivamente sobre temas locales, sino que son reproducciones o reescrituras de textos provenientes de la zona porteño-pampeana o del extranjero?; ¿cómo considerar a los escritores de folletines en diarios como El Orden, escritores no profesionales que provienen en su mayoría de la capital del país, que son extranjeros radicados en Argentina, o autores locales que se esconden tímidamente detrás de seudónimos o en el anonimato, y que no llegan a conformar un grupo específicamente contratado para elaborar dicha sección? En definitiva, ¿cómo situar geoculturalmente la producción literaria presente en la sección del folletín de El Orden de fines del siglo XIX, si no se reconoce en ella la producción literaria de un autor nativo de la región? ¿Acaso debemos descartar o renunciar a su estudio? Cuestiones que remiten de alguna manera a las polémicas sobre el planteo de un canon literario, gestadas en torno al texto de Harold Bloom, The western canon (1994) [El canon occidental (1995)], estrechamente vinculadas al terreno educativo (Pozuelo Yvancos, 1996) y, en nuestro caso, trasladadas al ámbito de la investigación para una revisión de historias literarias nacionales. Según Jorgelina Núñez (24 de enero de 1999)

[...] lo interesante, más allá del placer de confeccionar listas o realizar encuestas, o de la susceptibilidad que despierta el establecer sistemas de inclusión y de exclusión, radica en observar dos fenómenos curiosos: el primero, que la literatura como experiencia no es asunto de debate y sí lo es en tanto objeto de preservación y de enseñanza. $Y$, el segundo, que los problemas vinculados a la idea de canon -entre ellos el de la tradición- afectan a la literatura de una manera esencialmente distinta 
de la que concierne al resto del arte, lo cual confirma que la nuestra continúa siendo -mal que les pese a algunosuna cultura letrada. (p. 14) ${ }^{1}$

Para el contexto argentino, cabe mencionar otro canon, el de un grupo de intelectuales que polemizan acerca del canon literario a partir del planteo de Bloom en artículos publicados en revistas académicas diversas, reunidos por Susana Cella en Dominios de la literatura acerca del canon (1998). El texto pone en evidencia, según Núñez (1999), que "la cuestión ya estaba instalada mucho antes de la aparición del controvertido libro" (p. 14).

De las reflexiones recopiladas por Cella, llaman particularmente la atención las observaciones de Susana Zanetti (1998). Esta autora señala la ausencia de una academia supranacional que establezca las normas del canon de la literatura latinoamericana, así como "el carácter errático de sus lecturas y relecturas y la carencia de interpretaciones críticas reiteradas" (p. 92), entre los problemas más importantes que justifican el débil afianzamiento de dicho canon. Sin embargo, si bien es cierto que no existe tal academia rectora, se sospecha que sí se pueden reconocer centros metropolitanos desde donde se establecen las reglas del canon literario latinoamericano, variables según cada país.

Las cuestiones planteadas más arriba llevan a considerar la problemática del canon enfocada en la historia literaria desde una perspectiva pluralista, como la propuesta por José María Pozuelo Yvancos (1996), para superar las polémicas estériles de su legitimidad. Para ello, se siguen los aportes teóricos

1 Lo resaltado pertenece al original. de Roger Chartier (2005), concretamente lo relativo a las "representaciónes sociales" de determinadas categorías y la cuestión de las prácticas de lectura y de escritura. Un trabajo que se toma aquí como modelo es el de Carmen Elisa Acosta Peñalosa (2009): Lectura y nación: novelas por entregas en Colombia, 1840-1880. Si bien la autora delimita las novelas por entrega de Colombia como su objeto de estudio, el formato y la materialidad con que se presentan al público lector, a saber, la sección del foletín de la prensa diaria, y el modelo teórico adoptado (Chartier) - el enfoque en los modos de control de la producción de sentido de las obras frente a la libertad y la rebelión que implica el acto de leer (Acosta Peñalosa, 2009) - , son puntos de contacto, de encuentro y de diálogo con nuestro trabajo.

\section{Posturas de la crítica EN TORNO A LA LITERATURA PUBLICADA EN LA PRENSA DE PROVINCIAS}

El abordaje como objeto de estudio de la sección "Folletín" de los diarios latinoamericanos publicados entre fines del siglo XIX $y$ principios del xx no resulta una tarea sencilla. Por tratarse de un objeto difícilmente aprehensible, dicha sección ha sido escasamente considerada desde la perspectiva de su materialidad ligada conjuntamente a las prácticas periodística y literaria. Por lo general, la recuperación de las novelas originalmente publicadas en la sección del folletín de la prensa diaria va acompañada por estudios sobre los detalles de su edición, sobre la importancia de recuperarla para la historia de la llamada "literatura universal" junto con un breve análisis de su contenido. 
Esta metodología de presentación de la obra recuperada induce a la inevitable identificación de la sección del folletín con el género narrativo novela, y se descuida así la complejidad de dicha sección como parte de un impreso periodístico y de su relación con los escritores y los anónimos lectores.

En los trabajos académicos sobre el corpus novelístico canónico universal se leen, en reiteradas ocasiones, argumentos que justifican la exclusión del análisis de los textos publicados en formatos diferentes al libro y que circulan por vías alternativas como la prensa, modalidades consideradas "populares" o masivas, y por ello mismo descartados como obras sin valor. En este punto, se coincide con Carlos Hernán Sosa (2009) cuando señala la exclusión de los folletines nacionales de los compendios de historias de la literatura argentina.

La exclusión del corpus de investigación de este tipo de secciones y de su contenido entre el que se cuenta el novelítico - se fundamenta, en la mayoría de los casos, en su calidad literaria considerada pobre y en su carácter aparentemente localista, lábil, evanescente y olvidable, además de la dificultad de su abordaje como objeto de estudio. La labor de archivo que implica el estudio de la sección del folletín de la prensa diaria es una tarea que pocos investigadores o proyectos de investigación han emprendido con entusiasmo y muchos han abandonado a medio camino por percibirla como infructuosa, sobre todo, dado que el material se torna por momentos imposible de recuperar. Esta situación conduce a la negación de su existencia o a la desvalorización de lo existente como objeto de investigación viable. Uno de los riesgos de esta actitud frente a un objeto de estudio complejo y evanescente resulta ser la desvalorización de obras de autores, posteriormente consideradas como magistrales, y el descuido de la poderosa influencia adquirida por su difusión a través de la prensa diaria. En este sentido, cabe recordar los cuestionamientos a la categoría obras completas de un autor, por cuanto dejan de lado su producción publicada exclusivamente en la prensa periódica, en diarios íntimos o bitácoras de viajes, en cartas, álbumes, polémicas, etc. Tal es el caso de las llamadas "obras completas" de Rubén Darío, paradójicamente siempre incompletas (cfr. Montaldo, 2013, pp. 47-48), así como las de la mayoría de los considerados grandes escritores.

En el caso particular del campo académico argentino, las tareas de relevamiento del material de textos literarios y polémicas estéticas de la prensa diaria del siglo xIX han sido emprendidas por investigadores como Román Setton, quien recupera textos de Luis Varela (2009 y 2012) en su investigación sobre los orígenes del policial en Argentina; Luis Marcelo Martino (2012), quien lleva a cabo la recolección de polémicas literarias publicadas y protagonizadas por autores rioplatenses en la prensa uruguaya prácticamente desconocidas que representan el punto de vista regional de disputas estéticas europeas como la del clasicismo y romanticismo; Hebe B. Molina (2011) y Beatriz Curia (2010), quienes han recuperado un corpus importante de novelas escritas por mujeres; así como la puesta en valor de los escritos de Eduarda Mansilla de García llevada a cabo por un grupo dirigido por María Rosa Lojo, en torno al Proyecto de Investigación Plurianual del Consejo Nacional de Investigaciones Científicas y Técnicas 
(Conicet) N 0286: “Eduarda Mansilla: la biografía. Redes familiares y amicales. Los epistolarios. Los escritos dispersos. Hacia un estudio crítico integral", en conjunto con un sector de la familia de la autora. De dicha labor, cabe destacar la recuperación y el rastreo de los escritos de Eduarda publicados en diarios porteños, a cargo de Marina L. Guidotti (2015). En todos los casos mencionados se trata de obras de escritores porteños o rioplatenses, a excepción de Hebe Molina, quien incluye autores extranjeros y publicaciones de algunas provincias argentinas y países latinoamericanos como Perú (cfr. Molina, 2011, pp. 297 y ss.). Un fenómeno similar se percibe en Colombia, donde un grupo de investigadores, entre ellos Carolina Alzate (cfr. 2008, pp. 24-36), inició hace ya algunos años la tarea de rescate $y$ puesta en valor de la producción de escritoras colombianas del siglo XIX, marginadas y relegadas del corpus narrativo nacional.

En el caso de las provincias del interior de Argentina, la negación del material publicado en la sección del folletín de algunos diarios locales ha sido uno de los obstáculos más significativos de las investigaciones centradas en su producción literaria y cultural nacional, sobre todo de lo que corresponde al aporte de la región noroeste. Particularmente, en Tucumán, provincia considerada central para la región del noroeste argentino entre fines del siglo xIx $\mathrm{y}$ principios del xx por el desarrollo de la actividad azucarera, ${ }^{2}$ no se ha realizado un estudio sobre la presencia de dicha sección en el diario El Orden (1883-1943), uno de los periódicos más influyentes de la región

2 La posición central o dominante de Tucumán en la región noroeste de Argentina entre siglos se encuentra avalada por argumentos de índole histórica (Cfr. Bazán, 2004, pp. 48 y 49). en la época referida. Según la hipótesis acá planteada, el desconocimiento por parte de los estudiosos de la producción -y reproducción - literaria difundida por este medio periodístico se explicaría, por un lado, por un "desinterés condicionado" de los investigadores locales por priorizar materiales que abordan cuestiones lejanas del centro rioplatense (como una especie de reflejo centralista inevitable ante la justificación de subsidios de proyectos de investigación); por otro lado, por estudiar textos literarios que no ingresarían dentro del hegemónico folklore argentino y, por lo tanto, no constituirían la materia nativista ni criollista legítima de un estudioso de provincias, de la que se nutre aparentemente la cultura nacional, en el sentido ampliamente aceptado y dominante derivado de Joaquín V. González y Ricardo Rojas (Romano, 2000/2001 y Poderti, 2000), entendida como suma totalizadora de la producción cultural originaria de las regiones argentinas (a saber, el corpus que conformaría su tradición). Según este último sentido, pareciera que el investigador literario se encuentra en la disyuntiva de delimitar su corpus de investigación entre textos literarios canónicos nacionales o textos que conforman un corpus folklórico regional, igualmente canónico.

Por otra parte, podemos advertir que el desconocimiento por parte de los estudiosos del material literario difundido por $\mathrm{El}$ Orden podría explicarse por el exitoso mecanismo de naturalización de creer en la inexistencia de la sección del folletín en la prensa del interior del país, especie de postura ideológica ejercida desde los mismos claustros universitarios, ${ }^{3}$ fundada mayo-

3 No debe interpretarse "ideológico" en este contexto como una postura doctrinal específica, sino como proceso de naturalización de 
ritariamente en la influyente postura de los grandes centros metropolitanos, como Harold Bloom desde la academia norteamericana, que defiende la idea de que el valor de las obras no es otorgado por los críticos, sino por los escritores en la originalidad de la puesta en escritura de sus ideas frente a la tradición, lo que persiste y trasciende en tiempo y espacio: "El valor literario se establece por generaciones de poetas, novelistas y dramaturgos que han tenido que luchar contra la influencia de escritores particulares, una influencia que consideran ineludible. Y haciendo eso, establecen el valor. Realmente no importa lo que dices de ellos" (Bloom, 8 de febrero de 2013).

Esta postura presente entre los estudiosos locales - reproducida, como se sabe, en la mayoría de los países latinoamericanosconfirmaría en la práctica las observaciones realizadas anteriormente desde el terreno sociológico por el norteamericano Edward Shils (1959), sobre

[...] la inevitable e ineludible relación desigual entre metrópolis y provincia. Partiendo de la premisa de que "En todo sistema social existe un centro del que emana la autoridad y al que se rinde acatamiento", Shils enuncia

ideas puesto en marcha por determinado grupo de académicos de acuerdo con intereses propios de un sector dominante del campo intelectual y científico argentino contemporáneo en la lucha por una mayor asignación del presupuesto financiero estatal para proyectos universitarios.

Por otra parte, las necesidades didácticas de los programas de estudio vigentes han avalado de modo acrítico la enseñanza de ciertos clásicos literarios fosilizados en el sistema educativo, con una actitud impermeable a la integración de nuevos conocimientos y autores. Dicha situación de implementación obligatoria de prácticas diferentes - a saber, de docencia e investigación — desde y para las aulas ha generado una confusión entre investigar-enseñar sin salir de los clásicos universitarios y sin generar interés suficiente por nuevas tendencias. taxativamente que "en todo sistema social es inevitable una cierta desigualdad en la distribución del poder y el respeto", en el cual reconoce el "fenómeno de dominancia metropolitano" al que las provincias se resisten y del que se resienten (citado en Risco, 2015a, p.2).

De cierta forma, se pone en evidencia el comportamiento del "homo academicus propotípico" en el ámbito institucional universitario descripto por Pierre Bourdieu, tal como nos lo recuerda Gonzalo Navajas (2006), que por lo general "se ajustan con preferencia - aunque no siempre - a este modelo cultural, ya que garantiza la organización lógica y la clasificación y parcelación de las corrientes de los hechos culturales " (Navajas, 2006, p. 87).

En Argentina, esta postura se entronca con una tradición de estudios literarios hegemónicos nacionales, apoyados por los centros académicos internacionales, que sostienen la constitución de un campo intelectual ${ }^{4}$ argentino y su progresiva autonomización a partir de fines del siglo XIX, ligada al proceso de profesionalización del escritor concretada recién a principios del siglo xx. En estos estudios, el folletín argentino como género narrativo producto de la relación entre periodismo y literatura pareciera ser un fenómeno de una sola región, la pampeana, zona nucleada por el centro porteño bonaerense, tanto en su versión culta, proveniente de la así llamada "Generación del Ochenta", como en su versión popular, fundada

4 Se sigue la teoría del campo intelectual del sociólogo francés Pierre Bourdieu (1995), revisada y ampliada en las Reglas del Arte. Asimismo, son seguidas las observaciones de su aplicación al ámbito latinoamericano realizadas por Beatriz Sarlo y Carlos Altamirano (1997) en Literatura/Sociedad. 
en la literatura gauchesca-rural también pampeana porteña o rioplatense. Pedro Luis Barcia (2004), con respecto a las literaturas regionales dominantes en Argentina, reconoce la hegemonía de la producción literaria pampeana como metonimia simbólica de la literatura argentina: "En tanto, ha avanzado imperialmente una expresión regionalista particular, la gauchesca, que ejerce dos fuertes reducciones: una es restringir la poesía regional a lo pampeano, y la otra, reducir lo argentino al gaucho" (p. 32).

Este mismo predominio se observa también en la elección del corpus literario legítimo de investigación, dominante en la academia Argentina. Tanto es así que actualmente resulta necesario aclarar en ciertos círculos académicos que cuando se habla de "argentino" se entiende y se quiere entender el corpus de textos pertenecientes al circuito de producción y circulación de bienes simbólicos centrado en la zona pampeana representada por Buenos Aires, la capital autónoma (centro del país) y su amplia zona de su influencia. Esta tradición se vincula con ciertas consideraciones de la crítica actual elaboradas desde los centros metropolitanos hegemónicos de la propia academia universitaria argentina (nuevamente, Buenos Aires y su zona de influencia pampeana y rioplatense) y fortalecidas desde el interior de país por estudiosos que consideran más conveniente seguir líneas de investigación ya trazadas para conseguir visibilidad académica y reconocimiento intelectual en el centro del país. Esta postura de los investigadores del aparentemente relegado interior promueve una síntesis excluyente $\mathrm{y}$ circular que gira siempre en torno a un corpus de textos social y académicamente predeterminado.

\section{Centro y PERIfERIA EN LOS ESTUDIOS LITERARIOS ARGENTINOS: EL CASO DE TuCUMÁN}

Los estudiosos que buscan dar protagonismo a los modos de participación literaria de las regiones del interior en el corpus de la literatura argentina como sinónimo de nacional, específicamente la del noroeste argentino, toman como punto de partida el reconocimiento de ciertas renovaciones $y$ rupturas literarias originales producidas y trazadas, durante los años cuarenta del siglo $\mathrm{xx}$, en el terreno de la poesía $\mathrm{y}$, en los años sesenta, en narrativa.

La problemática de los géneros literarios en las zonas del interior de Argentina, es decir, en los circuitos provinciales, ha sido abordada por la crítica desde una perspectiva subjetiva. Como resultado, se ha construido una imagen de la producción narrativa que circula por las provincias, sobre todo por Tucumán, como pobre en contraposición con la prolífica y dinámica de Buenos Aires. Según la crítica, pareciera que el terreno de la poesía es el único cultivado con mediano éxito por los escritores de provincias, consideración que los estudiosos del tema comienzan a revisar y reformular hacia fines del siglo xx. Sin embargo, ya entrado el siglo xxI, algunos investigadores refuerzan esta postura a favor de la poesía como un modo de contrarrestar el predominio de estudios sobre narrativa argentina. Pero en ningún caso se detienen en la dinámica de la circulación de textos literarios, independientemente del origen del escritor que los produce.

La actitud reaccionaria hacia la narrativa se percibe claramente cuando los estudiosos 
abordan el desarrollo del género en Tucumán buscando un punto de vista innovador, original, que le otorgue esa particularidad necesaria para distinguirse entre las demás producciones y que le permita ingresar al canon. En este sentido, encontramos afirmaciones ambiguas como la de Octavio Corvalán (2008), un estudioso del tema que lo aborda desde su propio punto de vista de rescate provincial:

La narrativa del noroeste argentino ha sido singularmente rica. Su historia incluye nombres y títulos que el país todo ha aplaudido, incluyendo a muchos de ellos en su parnaso nacional [...]. En esta región, como en cualquier otra, se imbrican los nombres más fácilmente que en la Capital. Los maestros conviven sin dificultades con los discípulos y sólo de tarde en tarde los jóvenes se plantan ante los mayores para expresar su voluntad de distinguirse. Eso ocurrió con el grupo de La Carpa que fue un movimiento esencialmente lírico, aunque publicaron bajo su sello algunos narradores. La narración breve - no hay muchos novelistas, y este género parece haber llegado a su madurez sólo en tiempos muy recientes, con nombres como Libertad Demitrópulos, Héctor Tizón y Hugo Foguet - fue la que más se cultivó, y como se dijo más arriba, los autores más antiguos (Juan Carlos Dávalos, Luis Franco) seguían produciendo y de alguna manera dictando normas cuando las nuevas promociones habían entrado a la arena. Por eso es difícil señalar los hitos cronológicos en el desarrollo del cuento regional. Se puede afirmar que no hubo narradores hasta bien entrado el siglo XX.
Son precisamente los ya citados, más la participación, efectiva aunque esporádica, de escritores como Bernardo Canal Feijóo y Ricardo Rojas, los que enriquecieron la narrativa del noroeste con algunos textos ocasionales en su obra mayor. (p. 83) $)^{5}$

Otra valoración en la que Corvalán (2008) apoya su hipótesis del escaso desarrollo de la narrativa en la región gira en torno a la posibilidad de que los pocos narradores existentes hayan tenido seguidores o hayan formado escuela:

Las figuras de un Fausto Burgos (18821952) y de un Pablo Rojas Paz (18961956) tuvieron larga vigencia, pero fueron poco seguidas en la región misma. Sus novelas, narraciones, relatos, evocaciones de su lugar nativo fueron realizadas en Buenos Aires, o en otras provincias, a veces fuera del país y no despertaron el interés de los jóvenes. Éstos, por alguna extraña convicción, casi supersticiosa, prefirieron creer que ésta era una tierra de poetas (Es sabido que hay muchos versificadores, pero pocos buenos poetas en nuestra región literaria). (p. 84)

Según Corvalán, la narrativa "surge con cierto vigor y autonomía en la década del 40" (2008, p. 84). Menciona en primer lugar a Ángel María Vargas, autor de El hombre que olvidó las estrellas (1940); a Jorge W. Ábalos "más constante y 'profesional" en Cuentos con y sin víboras (1942); y, en tercer lugar, a Julio Ardiles Gray y su novela La grieta (1952). Recién se encuentran obras de narrativa significativas, para este crítico, a partir

5 El énfasis es mío. 
de 1960, época de su verdadero despegue productivo. El estudioso atribuye este entusiasmo de los prosistas de los años sesenta al apoyo de editoriales como Ediciones del Cardón, de Tucumán, y Tarja, de Jujuy y a organismos oficiales de cultura, los que a través de la institucionalización de premios y concursos fomentan la labor productiva local. Tal es el caso del Consejo Provincial de Difusión Cultural de Tucumán y las Direcciones de Cultura provinciales o municipales de Salta, Santiago del Estero y Catamarca (Cfr. Corvalán, 2008, pp. 84-85).

Por su parte, otro influyente estudioso de la literatura del noroeste argentino, David Lagmanovich reconoce que la mayoría de la producción literaria de los escritores de dicha región se edita en periódicos y revistas sobre todo a principios del siglo xx. Sin embargo, descarta estas producciones como objeto de estudio y de su propio panorama diacrónico de la literatura del noroeste, para centrarse únicamente en los libros publicados en las provincias que constituyen esa región argentina (Jujuy, Salta, Tucumán, Catamarca, Santiago del Estero y La Rioja). Coherente con su hipótesis de que en el noroeste argentino se produce mayormente poesía, no considera la posibilidad de abordar la narrativa del siglo xix que circula por la región, y limita su atención a la producción de mediados del siglo xx. En una breve síntesis, el crítico acota la historia literaria de principios del siglo $x x$, periodo en el que se destacan, a su entender, Fausto Burgos y Pablo Rojas Paz, quienes realizaron la mayor parte de su producción alejados de la región. Vemos aquí una evidente coincidencia de posturas entre Lagmanovich y Corvalán, ambas enunciadas desde centros locales no porteños. Para Lagmanovich (1974), el alejamiento de la provincia y el asentamiento del escritor en la capital metropolitana es la razón de su éxito y de su reconocimiento (p. 17). En este punto, se encuentra una aproximación a las afirmaciones de Manuel Gálvez, sobre todo cuando destaca a aquellos escritores de provincias que se deciden por residir en Buenos Aires para superar el provincialismo. Tanto Lagmanovich como Corvalán siguen en sus observaciones el modelo de literatura argentina implícito en Manuel Gálvez, derivado a su vez de R. Rojas, entendida como la suma de las producciones de autores de provincias, cuando este sostiene que a cada provincia le corresponde un par de escritores destacables que aportan su producción literaria a la literatura nacional (Cfr. Risco, 2015b). En este punto pareciera resonar nuevamente la observación de E. Shils cuando sostiene la necesidad de superar el provincialismo mental a través de la aceptación de su condición provinciana frente a la superioridad de la metrópolis integrándose a ella (Cfr. Risco, 2015a).

Por otra parte, Lagmanovich (1974) menciona, además, como casos aislados "exitosos" en narrativa - en cuanto que su fama trasciende de la provincia al continente sudamericano-, concretamente para el siglo xIX, a Juana Manuela Gorriti, de Salta, a quien descarta rápidamente de su consideración histórica de la literatura del noroeste por haber realizado la mayor parte de su obra fuera de Argentina (concretamente en Perú y Bolivia); y, por otra parte, las memorias del General Gregorio Aráoz de Lamadrid, de Tucumán, sin declarar el motivo de su exclusión del panorama histórico trazado (cfr. Lagmanovich, 1974, pp. 18-19).

Para este estudioso, a partir de los años sesenta del siglo $x x$ se producirán algunas 
obras significativas en narrativa. Nuevamente se percibe en esta afirmación una coincidencia con Corvalán. Dicha producción narrativa no logra superar a la lírica, según Lagmanovich, género predominante y fuertemente cultivado en la región:

Los rasgos característicos de la literatura del noroeste de Argentina pueden ser perseguidos, ante todo, sobre la línea temporal; [...]. Por razones de economía y método, conviene perseguir esa imagen siguiendo la línea de la poesía; y ello porque la producción poética supera, en esa parte del país, a la novelística, la ensayística, o la literatura teatral, tanto en volumen como en importancia. (1974, p. 17)

Hay que tener en cuenta que Lagmanovich reconoce en el prólogo de su libro como "autores nativos" de la región a aquellos escritores que hablan de esta en sus textos y que establecen en ellos y fuera de ellos una relación estrecha con la comarca y su gente: “[...]: no es - para mí- el nacimiento de un escritor en una provincia norteña lo que determina su ubicación, sino más bien la interacción con la comarca y sus gentes" (1974, p. 13).

Lagmanovich descarta la producción literaria del siglo xIX (no solo narrativa, sino también lírica y dramática) de su panorama histórico de la literatura del noroeste argentino empleando como argumento central la convicción personal de que en dicha región no existe obra tan significativa como la de un Echeverría o un Andrade (1974, p. 18). Por otra parte, este estudioso excluye la producción literaria de escritores como Juan Bautista Alberdi (oriundo de Tucumán), realizada, según Poderti (2000, p. 85), mayormente durante su exilio. Esta circunstancia podría haber motivado su exclusión de la producción literaria argentina, no específicamente tucumana. En este sentido, Pedro Luis Barcia (2004) sostiene que la primera obra "nativista" en prosa no ha sido escrita por un autor pampeano ni se focaliza en la pampa, ni tiene al gaucho como protagonista, sino que fue realizada precisamente por Alberdi. Su Memoria descriptiva de Tucumán de 1834, escrita a su regreso de Buenos Aires, constituye la primera obra de un nativo sobre su provincia natal, anticipándose, por un lado, a Esteban Echeverría, quien escribe la primera obra considerada nativista en poesía $-\mathrm{La}$ Cautiva (1837) - (cfr. Barcia, 2004, p. 26); por otro lado, a nuestro entender, se anticipa también al gesto supuestamente precursor de Joaquín V. González en Mis Montañas (1894) que materializa, según la crítica, su propuesta regionalista enunciada programáticamente en La Tradición Nacional (1887) (Romano, 2000/2001, p. 430). Desde mi perspectiva, cabe señalar que Alberdi y González representan posturas programáticas de diferente signo, formuladas en épocas político-sociales significativamente disímiles.

Sin embargo, el reconocimiento de Barcia excluye la tradición literaria de las primeras décadas del siglo xIx, que constituye la literatura de temática revolucionaria, en la cual los escenarios de Tucumán y Salta, entre otros, resultan significativos en la gesta independentista. Cielitos populares y odas letradas constituyen dicho corpus (como la Oda de la Batalla de Tucumán y de Salta, mencionadas por Juan Cruz Varela (1828) en el artículo "Literatura Nacional”). ${ }^{6}$

6 Agradecemos esta información al Dr. Luis Marcelo Martino. 
Por su parte, Mabel Susana Agresti (2005) considera la obra mencionada de Alberdi como uno de los primeros exponentes de "literatura provincial" en Argentina. Esta valoración de Agresti coincide con la vertiente filológica de la historia de la literatura argentina elaborada por Ricardo Rojas (1927) a principios del siglo xx. En efecto, en su texto Las provincias, uno de los ensayos publicado primeramente en 1922 por entregas en el diario La Nación en el que se basó el autor para confeccionar una parte de su famosa historia literaria, Rojas señala la importancia de la Memoria descriptiva de Tucumán de 1834 de Alberdi como el primer antecedente de las provincias argentinas centrado en su tierra natal. El crítico, además, destaca en dicho texto las similitudes que Alberdi encuentra entre el hombre tucumano y el porteño (cfr. Rojas 1927, pp.133-134).

Las apreciaciones subjetivas de Lagmanovich con respecto a la escasa actividad literaria durante el siglo xIx en el ámbito tucumano podrían tener un punto de apoyo en las observaciones de Rojas de principios del siglo $x x$ en su obra anteriormente mencionada. Luego de destacar el rol significativo de los periódicos y revistas de fines del siglo xIx para el desarrollo cultural de la provincia, en los cuales existe una profusa producción literaria - que el autor no aborda en este ensayo-, Rojas sostiene que "la producción puramente literaria es casi nula en Tucumán antes de 1880"7 (1927, p. 142). Señala, además, que primero circuló un libro de versos de Florencio Sal y agrega que "ningún otro lo siguió de inmediato" (1927, p. 142). Sin embargo, reconoce que se leían "como si fueran cosas del terruño", los

7 El énfasis es mío. textos de Alberdi y de Nicolás Avellaneda. Además destaca instituciones educativas (como el Colegio San Miguel, el Colegio Nacional y la Escuela Normal), asociaciones intelectuales (la Sociedad Sarmiento) y personalidades extranjeras influyentes (como los franceses Amadeo Jacques y Paul Groussac) y los instruidos tucumanos que lograron un reconocimiento extra-provincial entre 1870 y 1880, década en la que se visualiza en Tucumán "una vibrante colmena literaria, cuyo rumor se extendía por todo el Norte. La bibliografía de esta década revela ese despertamiento [...]". (p. 143)

La diferencia entre Rojas y Lagmanovich resulta evidente. Además de la distancia temporal que separa la producción de cada estudioso, cabe señalar que el primero de los autores mencionados reconoce una importante producción literaria en la provincia durante las últimas décadas del siglo xIX, mientras que el segundo la excluye de plano por ser insuficiente. Como puede observarse, los argumentos de Lagmanovich - y de Corvalán - se asientan sobre apreciaciones subjetivas que buscan justificar la delimitación epistemológica de un objeto de estudio geoculturalmente situado, focalizado en un género literario específico $\mathrm{y}$, para Lagmanovich, además, en un período histórico particular. A este último estudioso mencionado le interesa, concretamente, la poesía contemporánea producida a partir de mediados del siglo xx. Esta delimitación conduce en la actualidad a tomar como punto de partida la idea ya establecida de que, en narrativa y en lírica, el noroeste argentino no ha producido obra significativa durante el siglo XIX, la que puede encontrarse, en el caso de la poesía, a principios del siglo $\mathrm{xx}$, como apática 
expresión de un modernismo tardío y, en narrativa, recién a mediados de dicho siglo.

Otra cuestión relacionada con la exclusión de la narrativa del siglo xIx por los estudiosos locales se deriva de la supuesta ausencia de un escritor nacional o regional que haya publicado sus relatos como folletines exclusivamente para El Orden. Por ejemplo, en el diario no se publica la producción de un escritor local que se asemeje en su repercusión receptiva al éxito de Eduardo Gutiérrez, como folletinista exclusivo del periódico porteño La Patria Argentina. Según Jorge B. Rivera (1980), dicho autor representa al “auténtico escritor profesional que escribirá a tanto la línea y que no prestaba desmesurada atención a los halagos de la crítica" (p. 237), y destaca su conquista de un público literario específico. En afirmaciones similares se apoya Alicia Poderti (2000) al abordar el tema del folletín en Argentina, y se detiene en la influencia del folletín libertario y la actitud de la prensa de las provincias del noroeste argentino que persigue la misma moda del folletín rioplatense en las páginas de los diarios de principios del siglo $x x$.

En el caso concreto de la literatura que circula en Tucumán, la supuesta ausencia de material similar al de Gutiérrez conduce a los estudiosos a la conclusión de que lo publicado en diarios y revistas durante el siglo XIX y principios del xx no tiene valor porque es reproducción de literatura extranjera. La crítica se encuentra frente a un conflicto (que en realidad ella misma crea y refuerza) planteado en términos de producción (investigable)-reproducción (descartable) de textos literarios de autores locales, oriundos de la provincia.

Estos argumentos ponen de relieve dos cuestiones importantes sobre la producción y circulación literaria en las provincias. La primera cuestión indaga sobre la legitimidad de la construcción de un canon de autores argentinos a partir del tipo de participación de los escritores en publicaciones periódicas del interior del país o porteñas, independientemente de su tipo de "compromiso" con lo local o nacional. La segunda problemática se centra en la exclusión de toda literatura considerada "extranjera" —es decir, no escrita por "nativos" ni "criollos" - reproducida, traducida o producida exclusivamente para ser publicada en diarios del interior o porteños. Esta segunda cuestión pone en evidencia la exclusión del corpus de los estudios académicos de todo aquello que no ingresa dentro del "canon" literario nacional, nativista y criollo, popular o culto. Por otro lado, la exclusión del estudio del folletín, como sección de diarios y como género narrativo, como parte de la producción literaria que circula en los diarios de la región del noroeste argentino implica la exclusión de la misma literatura canónica cuyos anticipios, promoción y primeros capítulos vieron la luz pública por entregas en los diarios argentinos, tanto aquellos textos identificados por algunos estudiosos como parte de la producción culta cosmopolita de los "gentlemen-escritores" (Viñas, 1964; Rivera, 1980) de los años ochenta del siglo XIx, como las novelas de Eugenio Cambaceres o de Eduardo Holmberg, así como la producción popular (Gutiérrez) considerada como "legítimamente" nacional.

Otras hipótesis sobre las razones de la exclusión de la literatura publicada en la prensa tucumana de fines del siglo XIX por los estudios académicos apunta a la línea conservadora de construcción del canon literario argentino entendido como la sumatoria de 
tradiciones regionales, teniendo en cuenta que dichas "tradiciones" constituyen por sí mismas un género narrativo particular. Esta vertiente es impulsada por Joaquín V. González, cuyo proyecto regionalista se presenta, por un lado, acorde a la política cultural promovida desde el Estado durante la presidencia de Julio Argentino Roca, y, por otro lado, en contraposición con el cosmopolitismo de la narrativa naturalista dominante a fines del siglo XIX (Romano, 2000/2001, p. 430).

Esta línea conservadora tradicionalista no incluye al folletín de vertiente letrada en el canon de la literatura regional, pensada, por otra parte, a partir de 1880, y excluye además la producción literaria de la época romántica e independentista (Romano, 2004, p. 165), pues el "alma autóctona" se manifestaría en las leyendas, creencias, costumbres, mitos, cantares que constituyen los discursos que conforman el "alma" del folklore local de cada región del país. Para esta perspectiva, el folletín se relaciona con la "gauchesca" o con la literatura derivada de la "gauchesca" de estilo urbano-rural, esencialmente porteño, como la de Eduardo Gutiérrez, ya mencionada, basada por ejemplo en leyendas, héroes-antihéroes o creencias locales (como Juan Moreira) (Rivera, 1980). Esta línea tradicional-conservadora de recuperación popular regional ha predominado en los estudios analizados. Sin embargo, puede verse que Ricardo Rojas, con posterioridad a González, realiza una propuesta pedagógica de recuperación de lo propiamente literario argentino, y así ingresa en este ámbito no solo la tradición oral - como legítima expresión popular-, sino también la versión letrada.

En este punto, cabría replantearse en qué sistema ingresa la literatura de las regiones o de las provincias argentinas en la distinción propuesta por Nicolás Rosa (1998) entre la literatura argentina y la nacional, dentro del espacio semántico:

La literatura nacional es una política de acuerdos literarios y engendra sistemas y no cánones y formas de políticas de escritura y políticas de lectura, sobre las políticas del lenguaje. La literatura argentina es local y se ramifica en diversas formas de espacio: locus, templus, pagus (literatura gauchesca), túmulos, criptas (toda la literatura sobre Eva Perón), cárceles (toda la literatura sobre las diversas dictaduras), verdaderos espacios de la extensión que se oponen a los espacios de la expulsión (indios, inmigrantes, migraciones internas, marginados y desclasados) literaturas que generan lenguas argentinas que van de la acracia (Néstor Perlongher) al imperialismo lingüístico (Osvaldo Lamborghini). La literatura argentina es un sistema histórico, pero no estadual, y funda territorios, zonas y fronteras y también señala la lucha por la posesión de esos territorios y por el derecho de marcar esas fronteras, lo que nos llevaría al canon de la crítica literaria argentina. (pp. 82-83)

Hacia fines del siglo xx y principios del xxI, entre quienes valoran las producciones/ reproducciones de folletines de autores locales o su presencia en diarios del interior, encontramos, entre otras, a Alicia Poderti (2000), Carmen Perilli (2010) y Vanesa Miseres (2012). Poderti y Miseres destacan la labor literaria de la salteña Juana Manuela Gorriti, abundante en folletines, como se sabe, y su influencia en la literatura escrita 
por mujeres más allá de los límites del noroeste argentino. Miseres recuerda que dicha autora fue desvalorizada por uno de los más destacados historiadores de la literatura argentina, precisamente Ricardo Rojas, quien considera su producción literaria "deleznable" desde el punto de vista del estilo literario, así como toda la producción de mujeres en Argentina (Miseres, 2012). Una exclusión que pone en evidencia la subjetividad prejuiciosa de la construcción de su historia de la literatura argentina.

Por otro lado, recién en las primeras décadas del siglo xxI los investigadores locales reconocen la presencia de folletines - como género narrativo - en la prensa tucumana. En primer lugar, se ubica el trabajo de María Delia Paladini (1971) sobre el folletín de Juan B. Terán, Fruto sin flor, publicado en 1921 en la colección La Novela del Norte, editada en la imprenta del diario El Orden. Este ensayo constituye un primer estudio que indaga sobre dicha problemática, retomado posteriormente por María Trinidad Esma, quien focaliza la temática de la inmigración francesa en dicho folleto, por Nilda Flawiá de Fernández (1990), quien se detiene en los aspectos narrativos de la obra de Terán, y por Ana M. Risco (2011), que complejiza las categorías de letrado y popular presentes en dicha obra. Por otra parte, la nota periodística de Honoria Zelaya de Nader (1995), que relata la experiencia de la escritura de folletines y novelas breves promovidas por la prensa tucumana de principios del siglo $\mathrm{xx}$, representa una segunda aproximación significativa a la misma problemática. En esta línea se ubica el reconocimiento posterior de Carmen Perilli de la presencia de "folletines franceses" reproducidos por el diario tucumano El Orden durante las primeras décadas del siglo xx, en vísperas del Centenario de la Independencia (Perilli, 2010, p. 7). El estudio de Paladini, la nota de Zelaya de Nader y el reconocimiento de Perilli representan los primeros aportes por parte de investigadores locales sobre la presencia de dicho material en la prensa tucumana de principios del xx. Sin embargo, ninguno de estos trabajos mencionados se remonta a su situación durante el siglo xIx.

\section{A Modo de Recapitulación FINAL Y CIERRE}

A partir de nuestra investigación centrada en la sección del folletín del diario El Orden de Tucumán, planteamos como propósito del presente artículo una revisión reflexiva sobre la representación de la crítica y la historia literaria local de la literatura que circula por la prensa tucumana de fines del siglo xIx. La revisión de los argumentos críticos nos permite aventurar hipótesis explicativas sobre las posturas de los estudiosos locales predominantes durante el siglo xx y percibir aires de cambio en los críticos de principios del xxI. Las primeras pueden reconocerse en aquellos sistemas literarios tradicionales donde la dinámica de inclusión y exclusión del canon es determinada por un centro que se impone a sus periferias. Entre las hipótesis planteadas en esta investigación, adquiere fuerza aquella que visualiza el predominio de un centro metropolitano de estudios literarios que determina el canon investigable que conformaría el corpus de la literatura argentina. Se percibe, asimismo, que esta determinación se efectivizaría a través de la naturalización de los juicios metropolitanos en desmedro de lo local en relación con el corpus literario 
argentino del siglo xix. Sin embargo, a fines del siglo $\mathrm{xx}$, los estudiosos, mediados por una fuerte resistencia y cierta oposición al canon académico, buscan superar una suerte de provincianismo crítico, apuntando, por un lado, al acatamiento de las reglas de la metrópolis científica en coincidencia con el quehacer del homo academicus; por otro lado, al cuestionamiento de temas y problemáticas excluidas, concientes de las contingencias del valor literario, cuestión expuesta por Bárbara Herrnstein-Smith (Avelar, 2011, p. 13), en una suerte de diálogo entre lo predominante y lo periférico, superando lo que Bloom (1995) consideraría como una “escuela del resentimiento" (p. 30).

\section{REFERENCIAS}

Acosta Peñalosa, C. E. (2009). Lectura y nación: novelas por entregas en Colombia, 1840-1880. Bogotá: Universidad Nacional de Colombia.

Agresti, M. S. (2005). El espacio de lo provincial en el siglo XIX memoria descriptiva sobre el Tucumán, de Juan Bautista Alberdi. Revista de Literaturas Modernas (35), 31-43. Recuperado de http://bdigital.uncu.edu.ar/96

Alberdi, J. B. (2000). Memoria descriptiva de Tucumán. En Escritos póstumos: memorias y documentos (pp. 155-173). Buenos Aires: Universidad Nacional de Quilmes.

Altamirano, C. y Sarlo, B. (1993). Literatural Sociedad. Buenos Aires: Edicial S.A.

Altamirano, C y Sarlo, B. (1997). Ensayos argentinos. De Sarmiento a la vanguardia. Buenos Aires: Ariel.

Alzate, C. (2008). María Martínez de Nisser: una opinión y un cuerpo que se exponen. Cuadernos de Literatura, 13(25), 24-36.
Avelar, I. (enero-junio, 2011). La construcción del canon y la cuestión del valor literario. Lecciones Doctorales, (8), 1-20.

Barcia, P. L. (2004). Hacia un concepto de la literatura regional. En G. Videla de Rivero y M. E. Castellino (Eds.). Literatura de las regiones argentinas (pp. 25-45). Mendoza: Universidad Nacional de Cuyo..

Bazán, R. A. (2004). La literatura de ideas del noroeste argentino. En G. Videla de Rivero y M. E. Castellino (Eds.), Literatura de las regiones argentinas (pp. 47-58). Mendoza: Universidad Nacional de Cuyo.

Block de Behar, L. (1984). Una retórica del silencio. Funciones del lector y procedimientos de la lectura literaria. México, D. F.: Fondo de Cultura Económica.

Bloom, H. (1995). El canon occidental: la escuela y los libros de todas las épocas. Barcelona: Anagrama.

Bloom, H. (8 de febrero de 2013). El valor literario nunca es establecido por un crítico. [Entrevista de Paula Escobar Chavarría]. La Nación. Recuperado de http://www.lanacion.com.ar/1552471harold-bloom-el-valor-literario-nuncaes-establecido-por-un-critico

Bourdieu, P. (1995). Las reglas del Arte. Génesis y estructura del campo literario. Barcelona: Anagrama.

Cella, S. (comp.) (1998). Dominios de la literatura acerca del canon. Buenos Aires: Losada.

Chartier, R. (2005). El mundo como representación. Estudios sobre historia cultural. Barcelona: Gedisa.

Corvalán, O. (2008). Contrapunto y fuga (poesía y ficción del NOA). Tucumán: Universidad Nacional de Tucumán.

Curia, B. (Ed.), Rosa de Rivera, M. (2010). María de Montiel. Novela contemporánea (1861). Buenos Aires: Teseo. 
Esma, M. T. (1982). La inmigración francesa a través de una novela de Juan B. Terán. Tucumán: Universidad Nacional de Tucumán.

Flawiá de Fernández, N. M. (1990). El discurso literario de Juan B. Terán. En Argentina en su literatura. Tucumán (5), 17-42.

Herrnstein-Smith, B. (1991). Contingencies of value: alternative perspectives for critical theory. Cambridge, Massachusetts and London, England. Printed in United States of America: Harvard University Press.

Lagmanovich, D. (1974). La literatura de noroeste argentino. Rosario: Editorial Biblioteca.

Mansilla de García, E. (2015). Escritos periodísticos completos (1860-1892). Buenos Aires: Corregidor.

Martino, L. M. (2012). ¿"Guerra de diarios" o "rencillas de escuelas"? Crónica de una polémica en la prensa uruguaya de 1840. Tenerife: Cuadernos Artesanos (31).

Miseres, V. (2012). Una nación para el norte argentino: viaje y política en La Tierra natal de Juana Manuela Gorriti. CiberLetras. Revista de crítica y de cultura, (29). Recuperado de http://www.lehman.cuny. edu/ciberletras/v29/miseres.html

Molina, H. B. (2011). Como crecen los hongos. La novela argentina entre 1838 y 1872. Buenos Aires: Teseo.

Montaldo, G. (2013). Guía Rubén Darío. En R. Darío. Viajes de un cosmopolita extremo (11-51). Buenos Aires: Fondo de Cultura Económica.

Navajas, G. (2006). El canon y los nuevos paradigmas culturales. Iberoamericana, VI(22), 87-97.

Núñez, J. (24 de enero de 1999). El canon, desde aquí. En torno al libro de Bloom. Cultura y Nación, Clarín, 14.
Paladini, M. D. (1971). Una novela de Juan B. Terán. Buenos Aires: Universidad de Buenos Aires, Instituto de Literatura Argentina "Ricardo Rojas".

Perilli, C. (2010). La Patria entre naranjos y cañaverales. Tucumán y el Primer Centenario. Revista Pilquen, XII(12), 1-9.

Poderti, A. (2000). La narrativa del noroeste argentino. Historia socio-cultural. Salta: Editorial Milor, Consejo de Investigación de la Universidad Nacional de Salta (Ciunsa).

Pozuelo Yvancos, J. M. (1996). Canon: ¿estética o pedagogía?. Ínsula. Revista de Letras y Ciencias Humanas, diciembre, LI(600), 3-4.

Risco, A. M. (2011). Inmigración francesa y cultura popular. Amerika, (5). Recuperado de http://amerika.revues.org/2597

Risco, A. M. (2015a). La provincia y la metrópolis: una tensión determinante en Manuel Gálvez. IV Congreso Internacional "Cuestiones Críticas". Rosario, Universidad Nacional de Rosario.

Risco, A. M. (2015b). Un mapa letrado del interior de Argentina bajo la óptica nacional de Manuel Gálvez 1900-1930. En N. M. Flawía, (Dir.), Momentos, textos y escrituras 1900-1930 (pp. 153-180). Buenos Aires: Corregidor.

Rivera, J. B. (1980). El folletín. Eduardo Gutiérrez. En Historia de la Literatura Argentina (217-240). Buenos Aires: Centro Editor de América Latina.

Rojas, R. (1927). Obras de Ricardo Rojas [Tomo XVII: "Las Provincias"]. Buenos Aires: Librería La Facultad.

Romano, E. (2000/2001). Origen, trayectoria y crisis de la narrativa regionalista argentina. Inti: Revista de Literatura Hispánica (52-53), 429-460. 
Romano, E. (2004). La parábola narrativa regionalista. En G. Videla de Rivero y M. E. Castellino (Eds.), Literatura de las regiones argentinas (165-182). Mendoza: Universidad Nacional de Cuyo.

Rosa, N. (1998). Liturgias y profanaciones. En S. Cella (Comp.), Dominios de la literatura acerca del canon (59-83). Buenos Aires: Losada.

Sosa, C. (2009). El rapsoda plebeyo de la pampa. En N. Flawiá (Dir.), Argentina en su literatura (pp. 219-237). Tucumán: Universidad Nacional de Tucumán.

Setton, R. (2012). Los orígenes de la narrativa policial en Argentina. Recepción y transformación de modelos genéricos alemanes, franceses e ingleses. Madrid-Fankfurt am Main: Iberoamericana-Vervuert.

Setton, R. (2013). El candado de oro. 12 cuentos policiales argentinos (1860-1910). Buenos Aires: Adriana Hidalgo.

Varela, J. C. (23 de julio de 1828). Literatura Nacional (quinto artículo). El Tiempo. Diario politico, literario y mercantil, (68).
Videla de Rivero, G. y Castellino, M. E. (Eds.) (2004). Literatura de las regiones argentinas. Mendoza: Universidad Nacional de Cuyo.

Viñas, D. (1964). Literatura argentina y realidad política. Buenos Aires: Jorge Álvarez Editor.

Waleis, R. (Luis Varela) (2009). La huella del crimen. Buenos Aires: Adriana Hidalgo.

Waleis, R. (Luis Varela) (2012). Clemencia. Buenos Aires: Adriana Hidalgo.

Weinberg, F. (1964). Juan Cruz Varela, crítico de la literatura nacional. Boletín de Literatura Argentina de la Facultad de Filosofía y Humanidades, 1(1), 29-63.

Zanetti, S. (1998). Apuntes acerca del canon latinoamericano. En S. Cella (Comp.). Dominios de la literatura acerca del canon (87-105). Buenos Aires: Losada.

Zelaya de Nader, H. (28 de mayo de 1995). Las novelitas de 10 centavos. El Periódico, (30), 1. 